\title{
Accessibility, urban form, and property value: A study of Pudong, Shanghai
}

\author{
ChengHe Guan (Corresponding Author) \\ NYU Shanghai \\ Harvard University \\ chenghe.guan@nyu.edu
}

\author{
Richard B. Peiser \\ Harvard University \\ rpeiser@gsd.harvard.edu
}

\begin{abstract}
The effects of metro system development and urban form on housing prices highly depend on the spatial temporal conditions of urban neighborhoods. However, scholars have not yet comprehensively examined these interactions at a neighborhood-scale. This study assesses metro access, urban form, and property value at both the district- and neighborhood-level. The study area is Pudong, Shanghai, where metro system development has coincided with rapid urban growth. Two hundred and seventy-nine neighborhoods from 13 districts of Shanghai are randomly selected for the district-level investigation and 31 neighborhoods from Pudong are selected for the neighborhood-level investigation. The analysis of variance shows that metro access is more positively correlated to property price in Pudong than other districts. The Pearson correlation, principle component, and ordinary least square regression analyses show that while accessibility attributes have a positive influence on housing prices, neighborhood characteristics also exhibit a pronounced impact on property price change over time. This study extends our knowledge on how metro system development interacts with landuse efficiency and discusses planning policies that correspond to different stages of development.
\end{abstract}

Keywords: Urban form, urban neighborhood, accessibility, property value, metro system, Shanghai

\section{Article history:}

Received: October 3, 2017

Received in revised form:

August 14, 2018

Accepted: September 28, 2018

Available online: November 20, 2018

Copyright 2018 ChengsHe Guan \& Richard B. Peiser

http://dx.doi.org/10.5198/jtlu.2018.1318

ISSN: 1938-7849 | Licensed under the Creative Commons Attribution - Noncommercial License 4.0

The Journal of Transport and Land Use is the official journal of the World Society for Transport and Land Use (WSTLUR) and is published and sponsored by the University of Minnesota Center for Transportation Studies. 


\section{Introduction}

Rapid transit, especially metro systems, have influenced urban growth and property values, producing a diversity of urban forms and city patterns (Smith, 1986). Some of the resulting spatial forms are more environmentally sustainable by inspiring low-carbon travel, promoting land-use efficiency, and encouraging building type diversity. Further investigations on the interactions of metro accessibility, urban form, and property value are in urgent need to address the challenges associated with global urbanization (World Bank, 2010).

Previous studies recognize that metro systems have significant impact on urban forms and formations (Pan, Shen, \& Zhang, 2009; Srinivasan, 2010). In the past century, transportation systems have dramatically changed urban landscapes (Smith, 1986), especially metro systems which interact with market forces and inform land-use policies in the long run. Scholars have studied the relationship between metro system accessibility and residential neighborhood property values in a variety of context (Hess \& Almeida, 2007; Dong, 2017). Most researchers conclude that property values go up as neighborhoods get closer to metro stops (Pan, 2013; Zhong \& Li, 2016). However, the relationship between neighborhood-scale urban form and metro transit is less conclusive and the question of how neighborhood-scale urban form and metro system accessibility interact with property values has not been thoroughly explored (Pan et al., 2009; Yang, Chen, Le, \& Zhang, 2016). For example, if the property value of an existing neighborhood, conveniently located near metro stops, is high, should future neighborhood developments be denser and/or more diverse? A number of physical, social, and economic variables should be considered regarding land-use planning, metro system investment, and real property development (Cao, Mokhtarian, \& Handy, 2009; Yang, 2010; Wang \& Zhou, 2017).

This study aims to investigate the interactions among metro system accessibility, residential property value, and neighborhood-scale urban form by answering the following question: What urban planning strategies can promote more efficient urban spatial structure? The next section briefly reviews the current literature on accessibility, property value, and urban form. The methodology section addresses explanatory variables. The results section presents our findings. The first discussion section focuses on accessibility and urban form and policy implications. The second discussion section focuses on the jobs-housing relationship, public service, and sustainable urban spatial structure. The conclusion section presents caveats and recaps the key contributions.

\section{$2 \quad$ Literature review}

Metro transit has been a consistent factor in creating a diversity of urban forms (Smith, 1986; Li, Walker, Srinivasan, \& Anderson, 2010). From the simple linear shape of Baltimore and Mumbai to the advanced circle-radial shape of Beijing and London, and the more recent grid network of Guangzhou and Shenzhen, the typologies of the metro system and urban development are closely connected (Angel, Parent, Civco, \& Blei, 2012). In the 1980s, large cities like Hong Kong and Singapore were developing their metro transit systems with high-density residential neighborhood already in place (Smith, 1986; Yang et al., 2016). In the 2000s, many large cities were developing and/or expanding extensive metro transit networks simultaneously with urban expansion and re-intensification.

In China, the superimposed and the concurrently-developed metro systems co-exist in large cities like Beijing and Shanghai (the former means a metro system was established after rapid urban expansions and the latter means both happened at the same time). This special circumstance having to do with the stage of development during which the metro system was built produces spatial conditions and urban forms that respond to metro system accessibility and property values. The most studied 
dimensions include accessibility to transport facility (Hess \& Almeida, 2007; Cao et al., 2009; Yang, 2010; Wang, Chai, \& Li, 2011; Ma, Liu, \& Chai, 2015; Yang et al., 2016; Dong, 2017; Guan, 2018), neighborhood typologies (Wang \& Chai, 2009; Feng, Dijst, Prillwitz, \& Wissink, 2013; Zhao, 2014; Guan \& Rowe, 2016), and built environment characteristics (Pan et al., 2009; Srinivasan, 2010; Yang $\&$ Chen, 2014).

Historically, accessibility to transport facility was a determinant of land development and economic growth (Smith, 1986). Bus service, including Bus Rapid Transit (BRT), light rail, and street cars are all traffic-dependent and the lack of long term stability means that they aren't suitable to be a "catalyst of development" in Chinese cities (Smith, 1986; Pan et al., 2009). Metro systems, on the other hand, can support Transit Oriented Development (TOD) that attracts investment and population because of its long-term stability and operational efficiency (Yang et al., 2016; Dong, 2017).

Many cities in China have observed this changing relationship between accessibility and urban form (Pan et al., 2009). Accessibility to existing metro stops, especially in high density areas, can produce robust ridership and reduce ongoing expenses (Yang et al., 2016). On the other hand, access to future proposed metro stations can change urban development patterns through land use right transfer and potential increases in local government revenues (Yang, 2010). Under the pro-growth policy of the National Development and Reform Commission (NDRC), the metro stations proposed and under construction are continuing to reshape the urban form of Chinese cities. Distance to the closest station and time traveled to city centers are both critical concerns. For example, living closer to a metro station can significantly change people's travel behavior (Wang \& Zhou, 2017).

Other studies reveal that proximity to city centers via metro have stronger influence on travel behavior than land-use patterns (Ma et al., 2015). Accessibility to employment is often considered in studies of the Chinese urban built environment (Yang, Shen, Shen, \& He, 2012). In recent years, low job accessibility has been observed in some parts of major Chinese cities such as Beijing (Yang, 2010) and Shanghai (Pan et al., 2009) due to suburbanization and increase in car ownership. The resulting longer commute time has encouraged people to live closer to metro stations (Yang et al., 2016).

In developed countries, neighborhood characteristics can be summarized into five D's: density of residential population, diversity of land use, design of urban block, distance to public transit, and destination of access (Ewing \& Cervero, 2010). In the Chinese circumstance, two C's are added to reflect local conditions: compactness measured by overall conservative building footprints that are less invasive of the surrounding environment, and connectivity measured by spatial proximity, physical closeness, and distance to culture (Guan \& Rowe, 2018). Population density is a key determinant for property development and land value (Peiser, 1989; Yang, 2010; Zhao, 2014; Guan \& Rowe, 2016). It is often regulated through zoning ordinances and planning policies which impose limits on building density as measured by floor area ratios (FAR). In Shanghai, most of the recent developments have FARs higher than 2.0. Some high-rise development can reach 10 or even higher. Chinese cities, in general, also have larger block-sizes and neighborhood size. The implications of the number of residential units in each neighborhood and the site area have not yet been thoroughly studied (Wang \& Zhou, 2017). Large developments can attract retail, commercial, and other public amenities. On the other hand, the scarcity of available large land parcels can potentially push larger development projects to the outskirts with reduced metro accessibility and longer travel time to city centers. In recent years, homogeneous building typologies in large development projects have received a large amount of criticism. In response, mixeduse developments are encouraged. Different types of neighborhoods can have far-reaching effects on property values. Neighborhoods can be categorized by binary variables such as location (urban versus suburban), density (high versus low), and year built (old versus new) (Handy, Cao, \& Mokhtarian, 2005). In China, neighborhoods are also often classified by their historical context (work unit versus 
non-work unit), social-economic class (market versus welfare), and spatial configurations (conventional versus modern) (Wang, Song, \& Xu, 2011).

Built environment characteristics including urban amenities, educational institutions, and public services are all important concerns for housing prices. In China, urban amenities are provided best in the inner-city areas (Zhao, Lu, \& de Roo, 2011). Schools, fresh food markets, hospitals, child care, and senior housing all contribute to a positive proximity premium. These facilities often attract relatively high-income population (Zhao et al., 2011). With a cultural heritage of placing high value on education, housing prices go up in top school districts. Convenient access to fresh food markets, an important component of Chinese urban residence since the post-reform period, has been challenged by continuous urban expansion. However, the growing concern about the health benefits of food and the highly consolidated fresh food e-commerce have re-boosted consumer demand. As health issues become a growing concern, hospitals, especially those ranked as "first-class grade three," are in short supply and tend to attract senior living communities close by. The changing population pyramid and the change of one-child policy both contribute to increasing demand for facilities such as child care and senior housing. By Chinese cultural standards, certain facilities create negative proximity premiums. To name a few, chemical factories, trash dumpsters, and waste disposal are all non-desirables.

In general, Chinese urbanization has distinct features compared with its western counterpart. Understanding the interactions among metro access, urban form, and property value needs not only to establish statistical associations but also to recognize the evolution of urban growth and neighborhood development. As Boarnet (2011) describes, it is fundamental to understand how a community's built environment has been developed in a specific way. The late 1980s marked the beginning of Chinese cities' rapid urbanization. Most of the urban neighborhoods inherited a work unit type of spatial configuration, a place of employment and residency. A common work unit has its own schools, shops, post offices, and other services. In the 1990s and early 2000s, economic growth was accompanied by a huge surge of metro system development: Shanghai (1993), Guangzhou (1997), Dalian (2002), Wuhan (2004), and Nanjing (2005) all established their metro systems. Together with the reopening of the metro systems in Beijing and Tianjin, major Chinese cities were experiencing reorganizations of the jobs-housing relationship. The market-oriented property developments were replacing traditional work unit neighborhoods. In cities where existing population density is high, accessibility to job and residential location choice create the underlying conditions for equilibrium of jobs-housing balance or nonequilibrium of spatial mismatch. By 2016, backed by the NDRC, 30 cities in mainland China have metro systems under operation and over 40 smaller cities with population between 1.5 million to 3 million have received approval and financial support from the central government to develop metro systems. This is a critical moment for rapidly urbanizing Chinese cities to find balance between rapid transit investment and urban growth.

\section{$3 \quad$ Methodology}

\subsection{Neighborhood selection}

The main objective of this study is to discover the distribution pattern of neighborhood property value and metro access and then to apply urban form variables to explain the differences. In China, urban areas are divided into district $(\mathrm{Qu})$, sub-district (Jiedao), and residential communities (Shequ), from large to small. Each residential community is composed of multiple residential neighborhoods (Xiaoqu). A neighborhood is regarded as the smallest division or a micro-district. A neighborhood often covers one or more urban blocks, built by a single developer, enclosed by walls or fences with guarded gates, 
and has its own neighborhood association. Our study area includes 13 districts of Shanghai that are accessible by metro lines. There are 10 central districts - Huangpu, Xuhui, Changning, Putuo, Zhabei, Yangpu, Jiang'an, Luwan, Hongkou, and Pudong (Zhabei and Luwan have been merged to Jing'an and Huangpu respectively) and 3 outer districts - Baoshan, Minhang, and Jiading. 279 neighborhoods are randomly selected for the study based on the location of metro stations. The random selection applies a computer-aided random sampling process involving the subsequent steps: In each district, those subdistricts served by metro are identified. For example, in Pudong District, 20 out of 31 sub-districts are identified. In each sub-district, all neighborhoods are assigned unique numbers. For example, in the Century Park Jiedao of Pudong District, 112 neighborhoods are labeled with numbers and put into the random sampling process. Initially, 35 neighborhoods are assigned to each of the 13 districts, which make the total amount to 455 neighborhoods. After the random sampling, ineligible neighborhoods are eliminated either because of insufficient data or limited number of residential unit transactions. After elimination, the total number is brought down to 279 . The number of selected neighborhoods for each district ranges from 17 in Jiading to 31 in Pudong.

\subsection{Statistical analysis}

A series of statistical analyses were applied including analysis of variance (ANOVA), pairwise correlation analysis, principle component analysis (PCA), and ordinary least square (OLS) hedonic regression analysis. We first employed the one-way ANOVA model, providing statistical inference for comparing multiple group means, to test the average resale residential property price and accessibility to metro station by district. As one of the most useful techniques in statistical inference introduced by Ronald Fisher, ANOVA has been applied as an exploratory tool to explain observations (Montgomery, 2001). We then applied a pairwise correlation test to reveal the associations among variables and if statistical data reduction is necessary. The Pearson test is adopted because it measures the linear correlation between two variables and provides an unbiased estimate when the adjusted correlation coefficient is used (Corder $\&$ Foreman, 2014). In addition, the Spearman test (1904) is adopted to assess monotonic relationships for non-linear relationships (Corder \& Foreman, 2014). Furthermore, the OLS and PCA analysis were applied to understand how accessibility affects residential property price and to reveal how the internal structure of urban form and access can best explain the variance in price. PCA is selected for this study also because of its integration with Geographic Information System (GIS) in recent years (Petrisor, Ianos, Iurea, \& Vaidianu, 2012).

First, analysis of variance is performed to reveal the different relationships between property value and metro accessibility at the district level. One-way ANOVA models were applied to test the differences among group means. Model 1 compares the average resale prices among the 13 districts. Model 2 compares access from residential property to city centers by metro. Model 3 compares the ratio of price over access by districts, which measures the relationship between price and access. Model 4 compares access by price and district. The formula can be written as:

$$
V_{i j}=\mu_{j}+\varepsilon_{i j}
$$

where $\mu_{j}=$ mean of the $j t h$ population, $\mu_{j}=\mu+\tau_{j}, \mu$ is the overall mean of the combined populations, $\tau_{j}$ is the deviation of the group mean from the overall mean, and $\varepsilon_{i j}$ is the random error term. The ANOVA tests reveal that neighborhoods in Pudong display different distribution patterns compared to other districts, which leads to further neighborhood-scale investigation of Pudong.

A pairwise correlation test is performed among the selected attributes using Pearson's correlation test. Spearman's correlation test is also applied to variables with ordinal numbers. The high correlations 
among the variables necessitate statistical data reduction. PCA methodology was adopted to inspect the underlying data structure and to produce a series of uncorrelated linear combinations of the variables that contain most of the variance. The formula is shown as the following:

$$
F_{i j}=a_{i} * b_{j}+e_{i j}, \mathrm{i}=1 \text { to } \mathrm{n}, \mathrm{j}=1 \text { to } \mathrm{p}
$$

where $F_{i j}$ are the elements of the matrix $F, a_{i}$ (scores) and $b_{j}$ (loadings) are f-vectors of parameters, and $e_{i j}$ are independent homoscedastic residuals. A resampling method called Bootstrapping was also performed to test the stability of the results.

The PCA tests constructed a smaller set of important factor variables. These variables were then applied to the OLS hedonic regression models. The purpose of the regression analysis is to find out which of the factors can explain the dependent variable - price and price change. The formula is presented as the following:

$$
\rho_{i}=\beta_{0}+\beta_{1} x_{1}+\beta_{2} x_{2}+\cdots+\beta_{j} x_{j}+\mu
$$

where $\rho_{i}$ is the price at a point in time and price change over time, $i=1$ to $5 ; x_{j}$ is the explanatory variables, $j=1$ to 28 ; $u$ is the error term.

\subsection{Attribute selection}

As mentioned earlier, metro systems can be the catalyst of development supporting TOD and producing high compactness in urban form (Diao, Leonard, \& Sing, 2017; Guan, 2018; Zhu \& Diao, 2016). Thus, capturing property price increases attributable to metro accessibility is a key factor to understand sustainable neighborhood configuration (Diao, 2015). In addition, access to city centers, employment centers, and other transit facilities should also be considered. Moreover, a temporal dimension should be added to the discussion of property price, urban form, and accessibility. Therefore, multiple year prices and price changes are incorporated into this research. Moreover, not all urban form characteristics affect property price and access in the same way (Diao \& Ferreira, 2010). Some attributes represent the conditions of external environments and others are internal structure of the built environment. In this research, 28 attributes were collected for the 31 neighborhoods selected in Pudong. The definitions of the attributes are listed in Table 1. The price data are collected from online real estate open source platforms (www.fang.com). The accessibility attributes are calculated using time-distance analysis (time to centers and distance to stations) and counted using ArcGIS analysis (bus, high-rise office, and commercial). The location of the high-rise office and commercial buildings are collected by the authors. The urban form attributes are acquired from both online real estate platforms and spatial analysis conducted by the authors. The attributes can be divided into the following categories: price (p), accessibility (a), and urban form. Urban form can be subdivided into form of surrounding environment (e) and built condition of the neighborhood (n). Price includes five variables: average resale price in 2012 (p1), 2017 (p2), 5-year price change from 2012 to 2017 (p3), 1-year price change (p4), and 1-month price change (p5). Accessibility includes seven variables: time to the city center (a1), distance to the closest metro station (a2), the number of current metro stations within $1 \mathrm{~km}$ radius (a3), the number of future planned metro stations within $1 \mathrm{~km}$ radius (a4), bus stops within $1 \mathrm{~km}$ radius (a5), high-rise office buildings (a6), and commercial enterprise (a7). Environmental variables include the number of non-desirable facilities (e1), kindergartens (e2), schools (e3), colleges (e4), level of security (e5), hospitals and clinics (e6), public services (e7), banks (e8), fresh food markets (e9), parks within 500m (e10). Neighborhood variables include neighborhood types (n1), building types (n2), density (n3), green space (n4), year built (n5), 
property management $(\mathrm{n} 6)$, the number of residential units $(\mathrm{n} 7)$, nearby residential neighborhoods (n8), parking per unit (n9), neighborhood entry gates (n10), and site area (n11).

Table 1: Definitions of the 28 attributes

\begin{tabular}{|c|c|c|}
\hline Category & Variable & Definition \\
\hline \multirow{5}{*}{ Price } & P1 Average Price (2012) & The average resale price of the selected neighborhoods in 2012 \\
\hline & P2 Average Price (2017) & The average resale price of the selected neighborhoods in 2017 \\
\hline & P3 Price Change 5 years & The average resale price difference between 2012 and 2017 \\
\hline & p4 Price Change 1 year & The average resale price difference between 2016 and 2017 \\
\hline & p5 Price Change 1month & The average resale price difference within one month in 2017 \\
\hline \multirow{7}{*}{ Accessibility } & al Time to Centers & Travel time to city centers (minute) \\
\hline & a2 Dist. to Station $(\mathrm{km})$ & Distance to the closest metro station \\
\hline & a3 Current Station $1 \mathrm{~km}$ & The number of existing metro stations within $1 \mathrm{~km}$ radius \\
\hline & a4 Future Station $1 \mathrm{~km}$ & The number of future planned metro stations within $1 \mathrm{~km}$ radius \\
\hline & as Bus $1 \mathrm{~km}$ & The number of existing bus stops within $1 \mathrm{~km}$ radius \\
\hline & a6 High-rise Office & The number of high-rise offices within $500 \mathrm{~m}$ radius \\
\hline & a 7 Com. & The number of commercial buildings within $500 \mathrm{~m}$ radius \\
\hline \multirow{10}{*}{$\begin{array}{l}\text { Urban Form - } \\
\text { Surrounding } \\
\text { Enviornment }\end{array}$} & el Non Desir. & The number of non desirable facilities within $500 \mathrm{~m}$ radius \\
\hline & e2 Kindergarten & The number of kindergartens within $500 \mathrm{~m}$ radius \\
\hline & e3 School & The number of schools within $1 \mathrm{~km}$ radius \\
\hline & e4 College & The number of colleges within $1 \mathrm{~km}$ radius \\
\hline & e5 Secur. & The level of security system installed \\
\hline & e6 Hosp. Clinic & The number of hospitals and clinics within $1 \mathrm{~km}$ radius \\
\hline & e7 Social Serv. & The number of social service facilities within $1 \mathrm{~km}$ radius \\
\hline & e8 Bank & The number of banks within $1 \mathrm{~km}$ radius \\
\hline & e9 Fresh Food & The number of fresh food markets within $1 \mathrm{~km}$ radius \\
\hline & e10 Park $(500 \mathrm{~m})$ & The number of parks within $500 \mathrm{~m}$ radius \\
\hline \multirow{11}{*}{$\begin{array}{l}\text { Urban Form - } \\
\text { Built Condition } \\
\text { of the } \\
\text { Neighborhood }\end{array}$} & n1 Neigh. Type & The variety of neighborhood typologies in the abutting area \\
\hline & n2 Build Type & Types of buildings based on spatial form and functionality \\
\hline & n3 Density (FAR) & Building density based on floor area ratio \\
\hline & n4 Green Space & Percentage of green and open space \\
\hline & n5 Year Built & The year that the neighorhood is first developed \\
\hline & n6 Prop. Fee (RMB) & Property management fee per month in Chinese Yuan \\
\hline & n7 Resi. Units & The number of residential units \\
\hline & n8 Nearby Reside. Comm. & The number of residential community within $1 \mathrm{~km}$ radius \\
\hline & n9 Parking & The number of parking space per residential unit \\
\hline & n 10 Main Gates & The number of gates \\
\hline & n11 Site Area (ha) & The area of land in hectare \\
\hline
\end{tabular}

\section{$4 \quad$ Results and analysis}

\subsection{Analysis of variance in Shanghai}

Figure 1 shows the spatial distribution of the 279 selected neighborhoods in Shanghai. The black bar represents price and white bar represents access. Visual inspections show that black bars are higher than white bars in the inner districts while the opposite happens in the outer districts. The explanation can be that property prices are higher in the inner districts and residential property developments are more 
influenced by TOD in the outer districts. Further investigations were performed to reveal the relationship between property price and metro accessibility using the analysis of variance (ANOVA) models.

Table 2 summarizes the results of the ANOVA models. Model 1, 2, and 3 exhibit high values for the F-test, which means price, travel time, and the ratio of price over access by district all produce good fits. The results of model 4 show that only districts show high variation that is statistically significant. It means districts at different development stages have different levels of accessibility to city centers. To unfold which district appears to have the most consistent price to access relationship, the underlying regression coefficients were examined. The regressions show that Pudong, the baseline group, has the largest variation of price to access relationship and the longest access time to the city centers, see Table 3. The next step is to further investigate why and how neighborhoods developed in Pudong districts are different from other districts in Shanghai.

Table 2: Access, price, and district (ANOVA test)

\begin{tabular}{llrrrrrr}
\hline Model & & Partial SS & df & F & Prob $>$ F & R-squared & Adj. \\
\hline 1 Price & District & $2.46 \mathrm{E}+10$ & 12 & 11.21 & 0.0000 & 0.3360 & 0.3060 \\
2 Access & District & 4226.19 & 12 & 33.18 & 0.0000 & 0.5995 & 0.5814 \\
3 Price/Access & District & 175.48 & 12 & 43.78 & 0.0000 & 0.6639 & 0.6487 \\
4 Access & Price, District & 6492.83 & 221 & 3.01 & 0.0000 & 0.9210 & 0.6146 \\
& Price & 2266.64 & 209 & 1.11 & 0.3277 & & \\
& District & 495.26 & 12 & 4.22 & 0.0001 & & \\
& Residual & 557.07 & 57 & & & & \\
& Total & 7049.90 & 278 & & & &
\end{tabular}

Table 3: Access and district (ANOVA test)

\begin{tabular}{lrrrrrr}
\hline District & \multicolumn{2}{c}{ Coef. } & Std. Err. & $\mathrm{t}$ & $\mathrm{P}>|\mathrm{t}|$ & \multicolumn{2}{c}{ [95\% Conf. Interval] } \\
\hline Pudong & \multicolumn{2}{c}{0 (base) } & & & & \\
Huangpu & -12.989 & 2.183 & -5.95 & 0.0000 & -17.3600 & -8.6189 \\
Xuhui & -10.320 & 2.064 & -5.00 & 0.0000 & -14.4529 & -6.1878 \\
Changning & -11.117 & 2.415 & -4.60 & 0.0000 & -15.9524 & -6.2821 \\
Putuo & -10.685 & 2.110 & -5.06 & 0.0000 & -14.9105 & -6.4597 \\
Zhabei & -12.086 & 2.131 & -5.67 & 0.0000 & -16.3541 & -7.8179 \\
Yangpu & -11.919 & 2.016 & -5.91 & 0.0000 & -15.9560 & -7.8829 \\
Jing'an & -12.497 & 2.928 & -4.27 & 0.0000 & -18.3602 & -6.6335 \\
Luwan & -12.383 & 2.204 & -5.62 & 0.0000 & -16.7962 & -7.9703 \\
Baoshan & -8.727 & 2.278 & -3.83 & 0.0000 & -13.2900 & -4.1650 \\
Minhang & -11.167 & 2.436 & -4.58 & 0.0000 & -16.0450 & -6.2898 \\
Hongkou & -11.970 & 2.017 & -5.93 & 0.0000 & -16.0092 & -7.9300 \\
Jiading & -10.447 & 3.731 & -2.80 & 0.0070 & -17.9186 & -2.9763 \\
cons & 26.307 & 4.868 & 5.40 & 0.0000 & 16.5603 & 36.0546
\end{tabular}




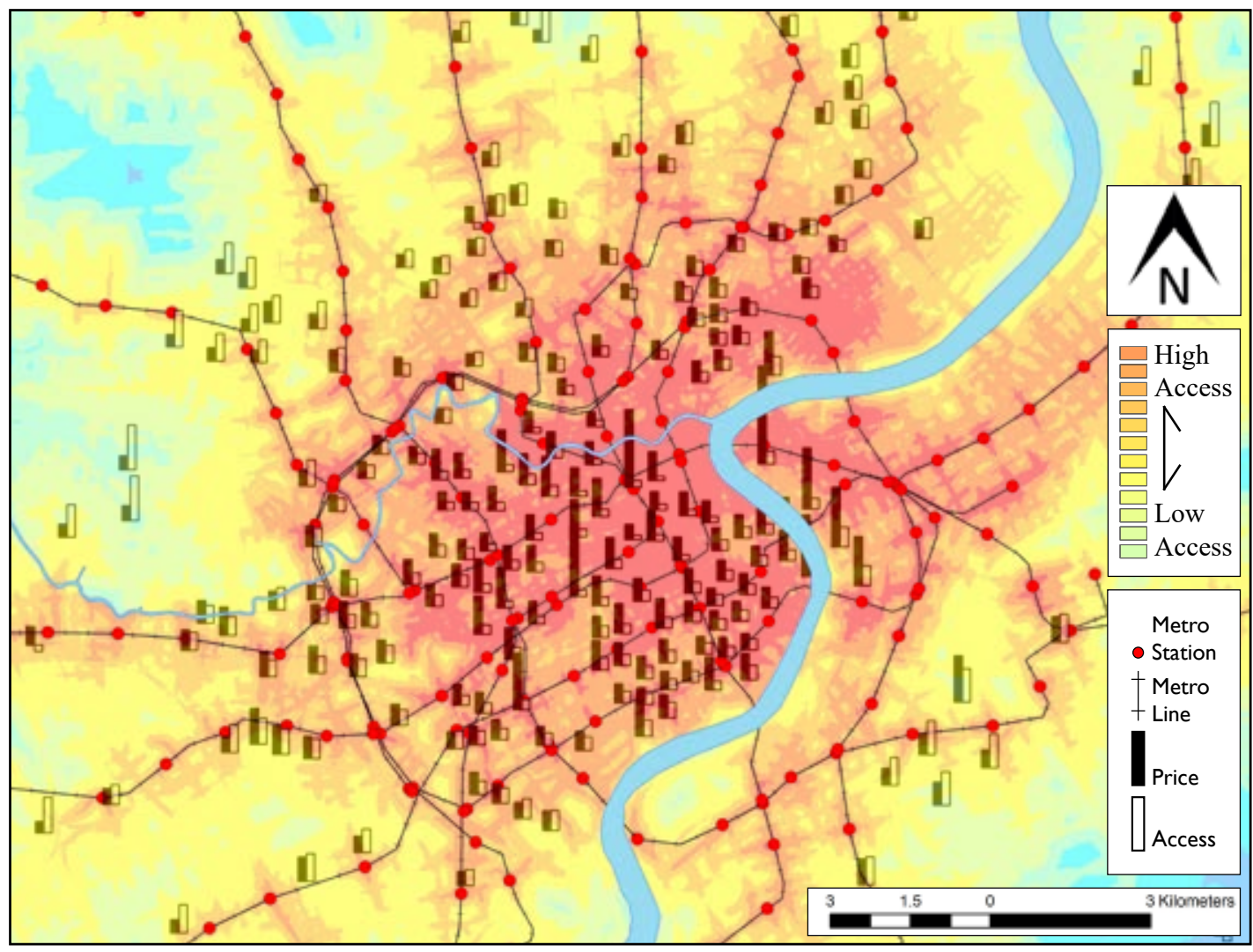

Figure 1: Metro access and property price of the 279 selected neighborhoods in Shanghai. The unit for property price is Chinese $\mathrm{RMB}$ (ranging from 8,700 to 160,000) and the unit for metro access is minutes (ranging from 0 to 90 ).

\subsection{Correlation between variables in Pudong}

An OLS hedonic regression model is introduced to understand neighborhood development and metro access in the Pudong District. Figure 2 shows the location of neighborhoods in relation to the existing metro stations and metro lines. Table 4 shows the correlation matrix of the 28 explanatory variables. The explanatory variables with statistically significant p-value at the 0.01 level are marked with asterisk $(*)$. Based on the covariance coefficients, a few pairs stand out: Short-term price change and future stations; price and job access; price and urban form; job access and urban form; metro access and neighborhood size; public services and bus access; density and access. In sum, these observations articulate the spatial 


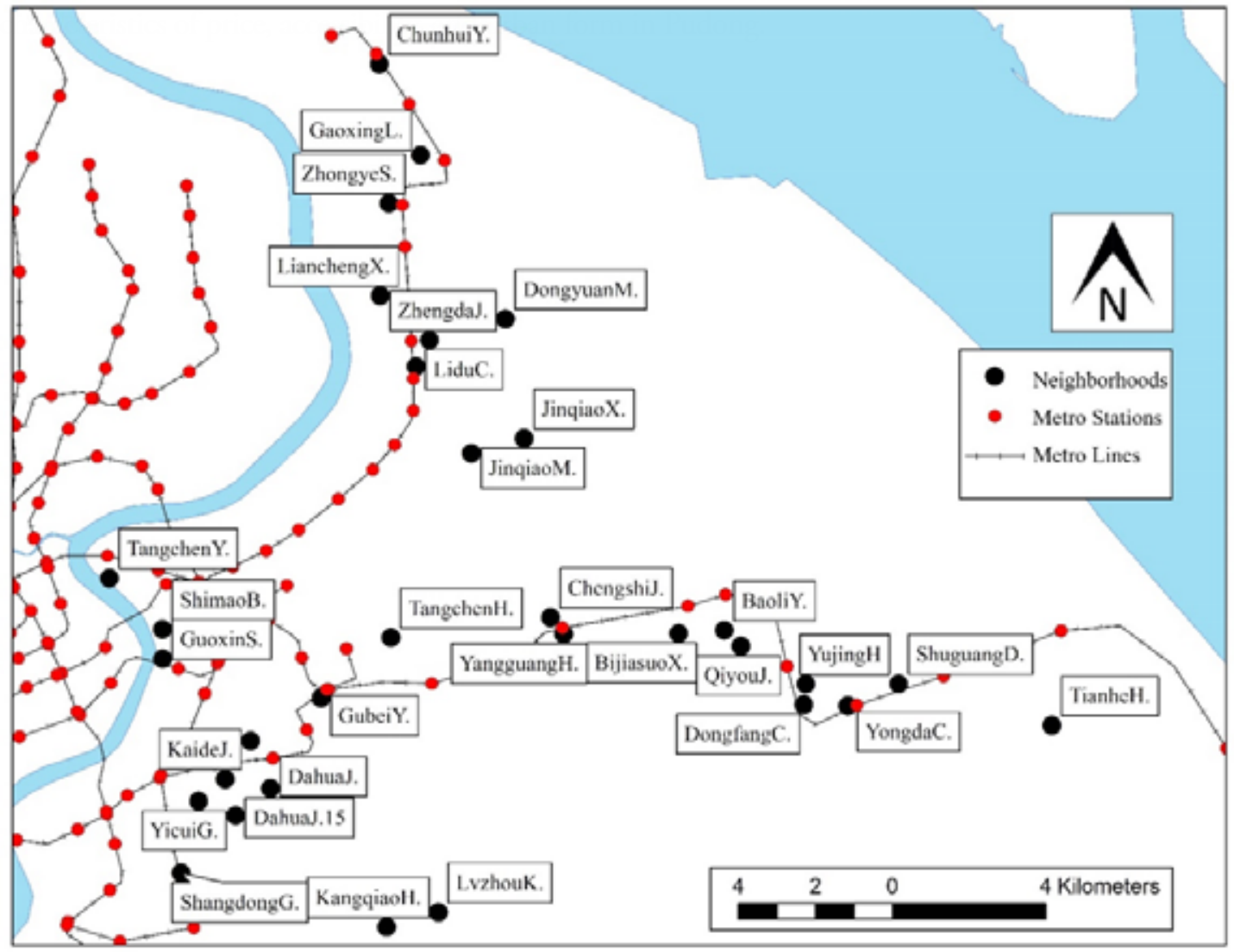

Figure 2: Locations of the 31 neighborhoods in Pudong District 
Table 4: Pairwise correlation coefficients matrix

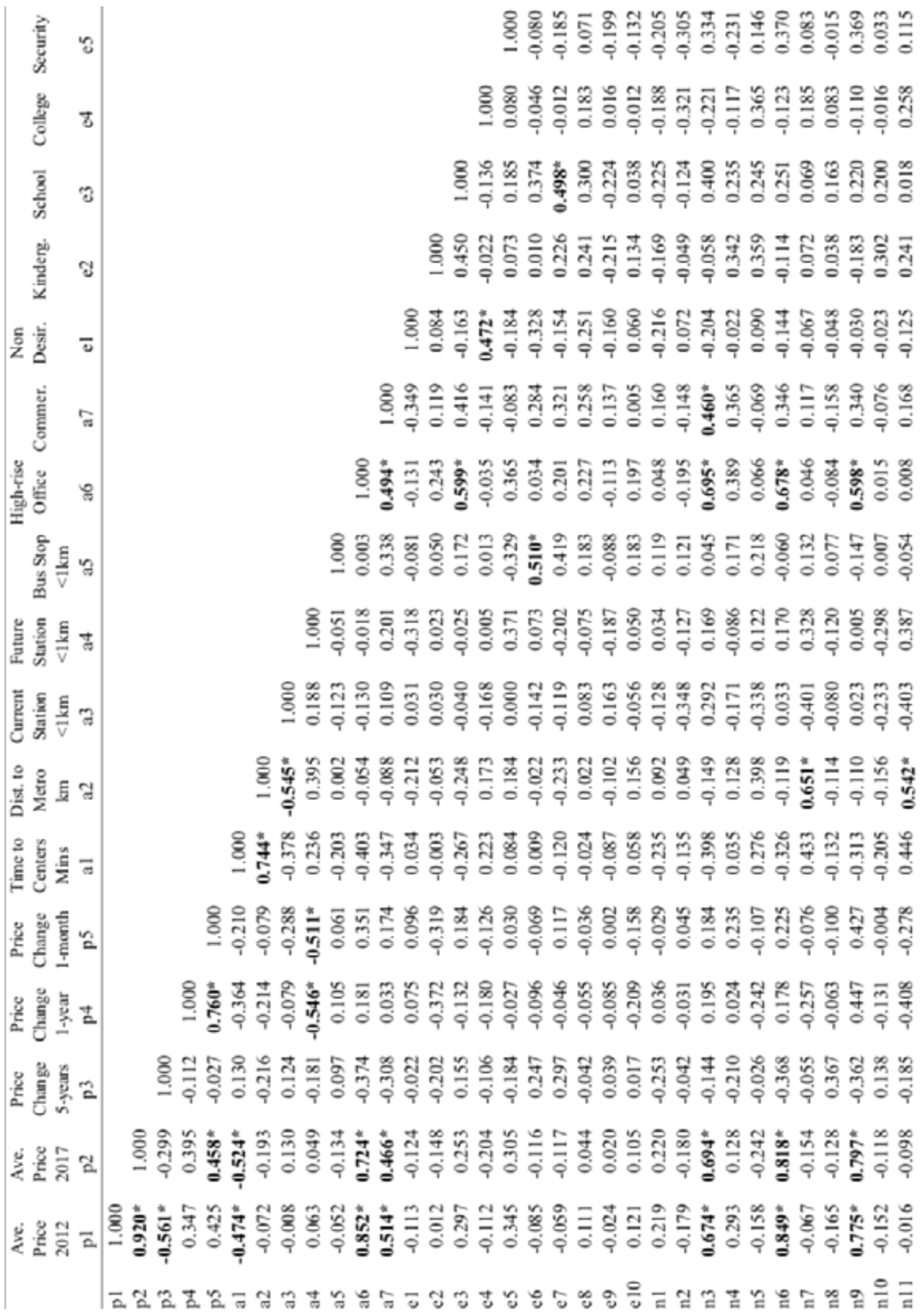


Table 4. (Continued)






\subsection{Factor identification using PCA}

Table 5 summarizes the loadings of the PCA tests. The loading coefficients lower than -0.25 or higher than 0.25 are in bold. Loadings with statistically significant p-value at the $0.1,0.05$, and 0.01 levels are marked with one, two, and three asterisks respectively. Factor 1 shows high coefficients for the number of high-rise office buildings and housing density. Factor 1 can be called "jobs-housing relationship." It represents the balance between accessibility to job opportunity and housing supply. In addition, commercial properties, quality of property management, and number of parking space per unit also exhibit high coefficients. The correlation analysis shows high positive associations between access to office and access to commercial as well as between density and parking. The property management variable reveals that in the jobs-housing relationship, not only the quantity of housing but also the quality of property maintenance matters.

Factor 2 shows high coefficients for travel time to the closest metro station and the size of the residential neighborhoods. The latter is represented by the number of residential units and site areas. Factor 2 can be called "size and access to existing metro station." Factor 3 is significant for the future planned metro stations and the (un)availability of public services such as post offices, public libraries, and civic centers. Factor 3 shows that the public service facilities are lagging behind public transit planning as a consequence of the government-led (State Council) "planning in advance" policy that prioritizes infrastructure development. In addition, level of security is also important. Security, often operated by private contractors, can contribute to public safety and emergency management. The positive correlation of security with factor 3 shows that the future planned metro stations are closer to neighborhoods where high security levels are provided. These neighborhoods are characterized by being recently built, high end, and often gated. Factor 3 can be called "public service and access to planned metro station." Since Factors 2 and 3 are only correlated with accessibility to a low to medium extent, the accessibility variables have been tested directly in the hedonic analysis. The coefficients are shown in Figure 3. The results show for property price in both 2012 and 2017, high-rise office and commercial are the two most positively correlated variables; for short term price change (one year and one month), future planned stations are the most negatively correlated variables. The results reinforce the PCA analysis: First, more value or benefit can be captured in the future in regard to access to planned metro station. Second, access to employment (office and commercial) are the most influential variables.

Factor 4 has high coefficients for neighborhood type and building type. Both are related to the typology of neighborhoods. Factor 4 can be called "typology." Factor 5 has high coefficients for fresh food markets, kindergartens, and non-desirable facilities. It can be called "public amenity." Factor 6 has high coefficients for parks and nearby residential communities. It can be called "environment proximity." Similar to factor 5, factors 7, 8, and 9 have high coefficients for kindergartens, fresh food markets, and non-desirable facilities. Together, these three factors are called "public amenity." Factor 9 also has high coefficients for residential units, which has been covered by factor 2 . Table $5 \mathrm{c}$ shows that these three factors are only correlated with environmental variables to a low extent. However, they certainly reinforce the collective influence of environmental proximity on property value.

Table 6 shows the variation explained by the PCA. Among the 28 factors, the top 6 factors together explained more than $64 \%$ of the variation in the original data. The top 9 factors explained $78.6 \%$ of the variation. Factor 7 to 28 each explain less than 5 percent of the variation and are thus eliminated from further discussion. The eigenvalue trendline flattens out after factor 6 , which also confirms the importance of factors 1 to 6 . Figure 3 shows the scree plot of PCA eigenvalues and the $95 \%$ confidence interval. 
Table 5a: Variable coefficient of the PCA

\begin{tabular}{|c|c|c|c|c|c|c|c|}
\hline & \multirow[b]{2}{*}{ Variables } & \multicolumn{2}{|c|}{$\begin{array}{c}\text { Factor } 1 \\
\text { Jobs-Housing } \\
\text { Relationship }\end{array}$} & \multicolumn{2}{|c|}{$\begin{array}{c}\text { Factor } 2 \\
\text { Size } \\
\text { Access to Metro E. }\end{array}$} & \multicolumn{2}{|c|}{$\begin{array}{c}\text { Factor } 3 \\
\text { Social Service } \\
\text { Access to Metro P. }\end{array}$} \\
\hline & & Coef. & $\mathrm{P}$-value & Coef. & P-value & Coef. & P-value \\
\hline al & Time to Centers & -0.2543 & 0.3330 & 0.2771 & 0.3450 & 0.1689 & 0.6170 \\
\hline a2 & Dist. to Station (km) & -0.1646 & 0.6190 & 0.3499 & 0.2550 & 0.2690 & 0.4600 \\
\hline a3 & Current Station $<1 \mathrm{~km}$ & 0.1173 & 0.6550 & -0.2770 & 0.1120 & -0.0110 & 0.9750 \\
\hline $\mathrm{a} 4$ & Future Station $<1 \mathrm{~km}$ & 0.0218 & 0.9210 & 0.1690 & 0.5910 & 0.2959 & 0.1880 \\
\hline a5 & Bus $<1 \mathrm{~km}$ & 0.0787 & 0.6940 & 0.1424 & 0.6340 & -0.2647 & 0.2660 \\
\hline a6 & High-rise Office & $0.3665^{\text {类类 }}$ & 0.0020 & 0.0930 & 0.7900 & 0.1024 & 0.6860 \\
\hline a7 & Commecial & $0.3027 * *$ & 0.0240 & 0.1109 & 0.7050 & -0.0382 & 0.8860 \\
\hline el & Non Desirable & -0.1361 & 0.3780 & -0.1035 & 0.6150 & -0.0298 & 0.9130 \\
\hline e2 & Kindergarten & 0.0664 & 0.7540 & 0.1925 & 0.3710 & -0.1547 & 0.5670 \\
\hline e3 & School & 0.2925 & 0.1040 & 0.1636 & 0.6090 & -0.1686 & 0.5060 \\
\hline e4 & College & -0.1052 & 0.5620 & 0.1517 & 0.4370 & 0.0269 & 0.9330 \\
\hline e5 & Security & 0.1210 & 0.5150 & 0.0770 & 0.8230 & 0.3021 & 0.1950 \\
\hline e6 & Hospital and Clinic & 0.1560 & 0.5140 & 0.2163 & 0.4850 & -0.2575 & 0.3560 \\
\hline e7 & Social Service & 0.1809 & 0.4610 & 0.1895 & 0.6440 & $-0.3782 *$ & 0.0970 \\
\hline e8 & Bank & 0.2031 & 0.3340 & 0.1974 & 0.4610 & -0.1501 & 0.6300 \\
\hline e9 & Fresh Food & 0.0133 & 0.9280 & -0.0778 & 0.6840 & -0.1125 & 0.6180 \\
\hline elo & Park $<500 \mathrm{~m}$ & 0.0653 & 0.6530 & 0.0853 & 0.6410 & 0.0771 & 0.7530 \\
\hline $\mathrm{n} 1$ & Neighborhood Type & -0.0290 & 0.8720 & -0.0860 & 0.7380 & 0.0996 & 0.8210 \\
\hline $\mathrm{n} 2$ & Building Type & -0.1920 & 0.2390 & -0.0809 & 0.7740 & -0.0775 & 0.8490 \\
\hline n3 & Density (FAR) & 0.3609 ㅊำ & 0.0010 & -0.0619 & 0.8630 & 0.1629 & 0.3980 \\
\hline n4 & Green Space & 0.1171 & 0.5750 & 0.1958 & 0.3520 & -0.1156 & 0.6990 \\
\hline n5 & Year Built & -0.0221 & 0.9370 & 0.2991 & 0.0440 & -0.0422 & 0.9090 \\
\hline $\mathrm{n} 6$ & Property Fee (\$) & $0.3423 * * *$ & 0.0090 & -0.0393 & 0.9200 & 0.2469 & 0.1830 \\
\hline $\mathrm{n} 7$ & Residential Units & -0.1178 & 0.7150 & 0.3548 * & 0.0650 & 0.1216 & 0.7600 \\
\hline $\mathrm{n} 8$ & Nearby Resid. Comm. & -0.0650 & 0.6720 & 0.0342 & 0.9000 & -0.2364 & 0.1720 \\
\hline n9 & Parking & 0.3044 * & 0.0540 & -0.0817 & 0.8330 & 0.2797 & 0.1290 \\
\hline $\mathrm{n} 10$ & Main Gates & -0.0836 & 0.6040 & 0.0000 & 1.0000 & -0.2146 & 0.4590 \\
\hline $\mathrm{n} 11$ & Site Area (h) & -0.0883 & 0.7910 & $0.3673 * *$ & 0.0470 & 0.1421 & 0.7150 \\
\hline
\end{tabular}

Note: ${ }^{* * *} 99 \%$ confidence level; ${ }^{* *}$ 95\% confidence level; * $90 \%$ confidence level 
Table 5b: Variable coefficient of the PCA

\begin{tabular}{|c|c|c|c|c|c|c|c|}
\hline & \multirow[b]{2}{*}{ Variables } & \multicolumn{2}{|c|}{$\begin{array}{l}\text { Factor } 4 \\
\text { Typology }\end{array}$} & \multicolumn{2}{|c|}{$\begin{array}{c}\text { Factor } 5 \\
\text { Public Amenity }\end{array}$} & \multicolumn{2}{|c|}{$\begin{array}{c}\text { Factor } 6 \\
\text { Environment } \\
\text { Proximity }\end{array}$} \\
\hline & & Coef. & P-value & Coef. & P-value & Coef. & P-value \\
\hline a1 & Time to Centers & -0.1625 & 0.5010 & -0.0983 & 0.6650 & 0.0560 & 0.7880 \\
\hline $\mathrm{a} 2$ & Dist. to Station (km) & 0.0634 & 0.8390 & -0.1137 & 0.5570 & 0.0243 & 0.9060 \\
\hline a3 & Current Station $<1 \mathrm{~km}$ & -0.2029 & 0.4030 & -0.1319 & 0.6820 & -0.1029 & 0.8090 \\
\hline $\mathrm{a} 4$ & Future Station $<1 \mathrm{~km}$ & -0.0186 & 0.9590 & -0.1613 & 0.6520 & -0.2761 & 0.4320 \\
\hline a5 & Bus $<1 \mathrm{~km}$ & 0.1447 & 0.6560 & -0.1606 & 0.6010 & 0.1340 & 0.7300 \\
\hline a6 & High-rise Office & 0.1310 & 0.6340 & 0.2405 & 0.2050 & 0.0678 & 0.8160 \\
\hline a7 & Commecial & 0.1855 & 0.4170 & -0.1879 & 0.4140 & -0.0249 & 0.9300 \\
\hline el & Non Desirable & -0.1547 & 0.6770 & 0.3179 & 0.4830 & 0.4142 & 0.2620 \\
\hline e2 & Kindergarten & 0.0080 & 0.9830 & 0.3341 & 0.1700 & 0.0212 & 0.9670 \\
\hline e3 & School & 0.0328 & 0.9200 & 0.2717 & 0.1800 & -0.1495 & 0.6180 \\
\hline e4 & College & -0.2732 & 0.2390 & 0.1309 & 0.7390 & 0.2209 & 0.5430 \\
\hline e5 & Security & -0.1667 & 0.6650 & 0.2367 & 0.5490 & -0.3265 & 0.2710 \\
\hline e6 & Hospital and Clinic & -0.0845 & 0.8190 & -0.2715 & 0.2420 & -0.1009 & 0.7820 \\
\hline e7 & Social Service & -0.0867 & 0.8080 & -0.0677 & 0.7570 & -0.0105 & 0.9560 \\
\hline e8 & Bank & -0.2218 & 0.3720 & -0.1397 & 0.6380 & 0.1107 & 0.7090 \\
\hline e9 & Fresh Food & -0.0521 & 0.8950 & -0.3790 & 0.0950 & 0.0220 & 0.9650 \\
\hline $\mathrm{e} 10$ & Park $<500 \mathrm{~m}$ & 0.1792 & 0.4850 & 0.0288 & 0.9530 & 0.4294 & 0.1110 \\
\hline n1 & Neighborhood Type & 0.4842 & 0.0140 & -0.1565 & 0.7380 & 0.0517 & 0.8760 \\
\hline $\mathrm{n} 2$ & Building Type & 0.4390 & * 0.0120 & 0.1232 & 0.7730 & -0.0148 & 0.9620 \\
\hline n3 & Density (FAR) & 0.0228 & 0.9110 & 0.0244 & 0.8880 & -0.0810 & 0.6330 \\
\hline n4 & Green Space & 0.1977 & 0.4140 & -0.0507 & 0.8960 & 0.2690 & 0.4430 \\
\hline n5 & Year Built & -0.2079 & 0.4210 & 0.1768 & 0.5510 & 0.1018 & 0.7730 \\
\hline n6 & Property Fee (\$) & 0.0625 & 0.8070 & 0.0051 & 0.9800 & 0.1082 & 0.5590 \\
\hline $\mathrm{n} 7$ & Residential Units & 0.1849 & 0.4110 & 0.0048 & 0.9850 & -0.1040 & 0.6320 \\
\hline $\mathrm{n} 8$ & Nearby Resid. Comm. & 0.0107 & 0.9740 & 0.1391 & 0.7490 & -0.3951 & 0.1630 \\
\hline n9 & Parking & -0.0113 & 0.9690 & 0.0739 & 0.7450 & 0.1244 & 0.6040 \\
\hline $\mathrm{n} 10$ & Main Gates & 0.2574 & 0.5070 & 0.3360 & 0.3360 & -0.1938 & 0.6410 \\
\hline n11 & Site Area (h) & 0.1211 & 0.6160 & -0.0350 & 0.8820 & -0.0723 & 0.7800 \\
\hline
\end{tabular}


Table 5c: Variable coefficient of the PCA

\section{Factor 7}

Public Amenity
Factor 8

Public Amenity
Factor 9

Public Amenity

\begin{tabular}{|c|c|c|c|c|c|c|c|}
\hline & Variables & Coef. & P-value & Coef. & $\mathrm{P}$-value & Coef. & P-value \\
\hline al & Time to Centers & 0.0552 & 0.8600 & -0.0268 & 0.9510 & -0.1253 & 0.8810 \\
\hline $\mathrm{a} 2$ & Dist. to Station $(\mathrm{km})$ & -0.1083 & 0.6620 & -0.0299 & 0.9620 & -0.1136 & 0.6840 \\
\hline a3 & Current Station $<1 \mathrm{~km}$ & 0.4675 & 0.5450 & -0.1306 & 0.9600 & 0.1067 & 0.9100 \\
\hline $\mathrm{a} 4$ & Future Station $<1 \mathrm{~km}$ & 0.2356 & 0.8890 & -0.2970 & 0.8260 & 0.1278 & 0.8820 \\
\hline a5 & Bus $<1 \mathrm{~km}$ & -0.2144 & 0.9190 & -0.3770 & 0.7630 & 0.2243 & 0.8010 \\
\hline a6 & High-rise Office & -0.0564 & 0.9530 & 0.1694 & 0.6300 & 0.0303 & 0.9250 \\
\hline a7 & Commecial & 0.1284 & 0.7640 & 0.0520 & 0.9480 & 0.2261 & 0.6480 \\
\hline el & Non Desirable & 0.0179 & 0.9740 & 0.0359 & 0.9500 & 0.3701 & 0.1690 \\
\hline e2 & Kindergarten & 0.4771 & 0.2340 & -0.0510 & 0.9850 & -0.1990 & 0.7470 \\
\hline e3 & School & 0.0370 & 0.9430 & -0.0858 & 0.7640 & 0.0006 & 0.9990 \\
\hline e4 & College & -0.1671 & 0.9150 & 0.2688 & 0.8060 & 0.3091 & 0.8210 \\
\hline e5 & Security & -0.0816 & 0.8680 & 0.0618 & 0.9140 & -0.1726 & 0.5570 \\
\hline e6 & Hospital and Clinic & -0.2400 & 0.7690 & -0.1431 & 0.9150 & -0.0445 & 0.9030 \\
\hline e7 & Social Service & -0.0428 & 0.8520 & 0.0047 & 0.9890 & 0.0876 & 0.8900 \\
\hline e8 & Bank & 0.0231 & 0.9840 & 0.1943 & 0.7080 & -0.3427 & 0.6380 \\
\hline e9 & Fresh Food & -0.0329 & 0.9900 & 0.4505 & 0.2470 & -0.1744 & 0.8210 \\
\hline e10 & Park $<500 \mathrm{~m}$ & 0.0998 & 0.9430 & -0.2371 & 0.7440 & -0.2053 & 0.7620 \\
\hline $\mathrm{n} 1$ & Neighborhood Type & -0.0486 & 0.9570 & 0.1509 & 0.7340 & -0.0857 & 0.9330 \\
\hline $\mathrm{n} 2$ & Building Type & -0.1553 & 0.8810 & -0.1840 & 0.8350 & -0.0767 & 0.8220 \\
\hline n3 & Density (FAR) & -0.0620 & 0.9250 & -0.1123 & 0.7880 & 0.1375 & 0.5860 \\
\hline n4 & Green Space & 0.3310 & 0.7820 & 0.2051 & 0.9130 & 0.0674 & 0.9540 \\
\hline n5 & Year Built & -0.2099 & 0.8790 & -0.2415 & 0.8440 & -0.2152 & 0.7910 \\
\hline n6 & Property Fee (\$) & -0.1545 & 0.6860 & 0.0616 & 0.9440 & -0.0043 & 0.9880 \\
\hline $\mathrm{n} 7$ & Residential Units & 0.0553 & 0.9200 & 0.0724 & 0.8940 & $0.3327 *$ & 0.0710 \\
\hline $\mathrm{n} 8$ & Nearby Resid. Comm. & -0.1590 & 0.8790 & 0.1699 & 0.8650 & 0.2594 & 0.5270 \\
\hline n9 & Parking & -0.2325 & 0.6290 & 0.0809 & 0.9500 & -0.0022 & 0.9950 \\
\hline $\mathrm{n} 10$ & Main Gates & -0.0190 & 0.9860 & 0.1886 & 0.6830 & -0.2473 & 0.7690 \\
\hline n11 & Site Area (h) & 0.1415 & 0.9210 & 0.2554 & 0.7560 & 0.1333 & 0.7930 \\
\hline
\end{tabular}


Table 6: Factor loading of the PCA

\begin{tabular}{lcccccccc}
\hline \multicolumn{2}{l}{ Component } & Eigenvalue & Std. Err. & \multicolumn{2}{c}{ [95\% Conf. Interval] } & Difference & Proportion & Cumulative \\
\hline Factor & 1 & 4.6691 & 1.1860 & 2.3447 & 6.9936 & 0.8715 & 0.1668 & 0.1668 \\
Factor & 2 & 3.7976 & 0.9646 & 1.9070 & 5.6882 & 0.6322 & 0.1356 & 0.3024 \\
Factor & 3 & 3.1654 & 0.8040 & 1.5896 & 4.7413 & 0.5922 & 0.1131 & 0.4154 \\
Factor & 4 & 2.5732 & 0.6536 & 1.2922 & 3.8542 & 0.4556 & 0.0919 & 0.5073 \\
Factor & 5 & 2.1176 & 0.5379 & 1.0634 & 3.1718 & 0.3515 & 0.0756 & 0.5830 \\
Factor & 6 & 1.7661 & 0.4486 & 0.8869 & 2.6454 & 0.3688 & 0.0631 & 0.6460 \\
Factor & 7 & 1.3974 & 0.3549 & 0.7017 & 2.0930 & 0.0445 & 0.0499 & 0.6959 \\
Factor & 8 & 1.3529 & 0.3436 & 0.6794 & 2.0264 & 0.1790 & 0.0483 & 0.7443 \\
Factor & 9 & 1.1739 & 0.2982 & 0.5895 & 1.7583 & 0.0677 & 0.0419 & 0.7862
\end{tabular}

Dimensionality assessment

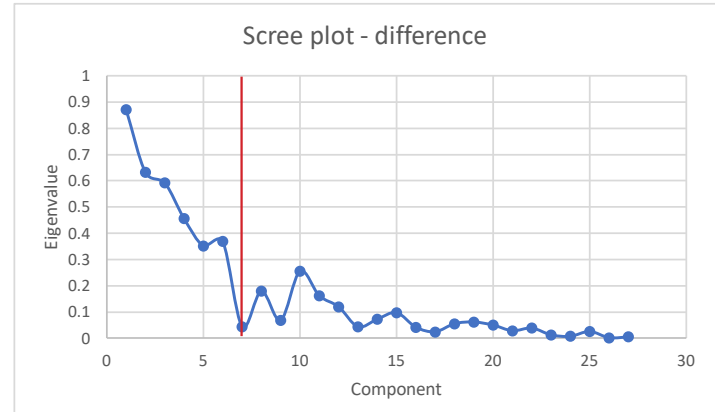

Difference between one eigenvalue and the next

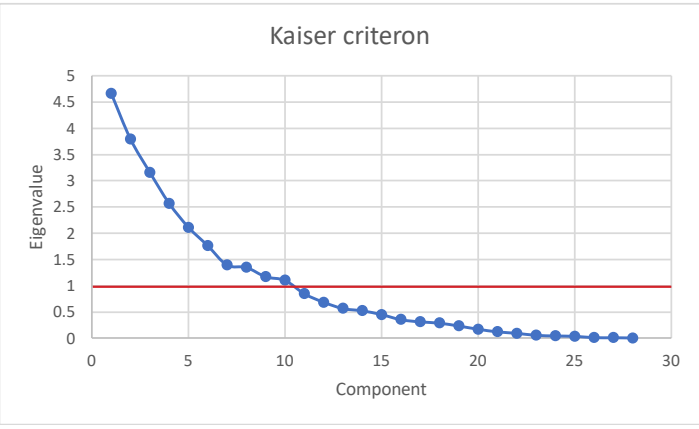

Eigenvalue $>1$ and/or proportion $>0.05$

Figure 3: Dimensionality assessment of eigenvalues using scree plot difference and the Kaiser criterion

\section{Metro system accessibility, jobs-housing relationship, and public service}

Table 7 summarizes the results from the five regression models on price and price change. Model 1 uses the property price in 2012 as the independent variable. Factor 1 "jobs-housing relationship" and factor 3 "access to metro and public service" show statistically significant p-values at the 0.001 level. Factor 4 "typology" is also statistically significant at the 0.01 level. The results reveal that the average resale price of neighborhoods in 2012 is a function of jobs-housing balance, access to metro plus public service, and neighborhood typology.

Model 2 regresses on the average price in 2017. Factor 1 "jobs-housing relationship" and factor 3 "public service plus access to planned metro" are statistically significant at the 0.001 level. The average resale price in 2017 can be understood as a function of jobs-housing balance and access to metro stations plus public service.

Model 3 uses 5-year price change from 2012 to 2017 as the independent variable. The significant factor is factor 3 "public service plus access to planned metro" at the 0.05 level. The price change over the last 5 years is a function of access to metro stations plus public service.

Model 4 applies 1-year price change from 2016 to 2017 as the independent variable. Factor 2 "access to metro plus size" is significant at the 0.05 level. In this factor, the access to metro focuses on existing stations that are under operation. 
In both models 1 and 2, jobs-housing relationship appears to be statistically significant. In this study, it is the most important factor influencing housing prices at a point in time. Jobs-housing balance has been the source of heated debates in the international context (Guiliano \& Small, 1993; Peng, 1997) as well as in China (Wang \& Chai, 2009). Cervero (1996) indicates that jobs-housing imbalance can cause higher vehicle miles traveled (VMT) and larger percentage of motorized travel mode. Weitz et al. (2003) states that jobs-housing balance is a process readjustment to market failure. In the Chinese circumstance, Wang and Chai (2009) claim that the work unit system has an inherited advantage for achieving better jobs-housing balance. In addition, Zhao et al. (2011) added to the claim that a comprehensive master plan implemented through government intervention can further enhance the housing resource allocation. The counter argument supporting co-location theory claims that the jobs-housing balance can be achieved through market forces (Hu, Fan, \& Sun, 2017). Hu, Sun, \& Wang (2018) extended the argument that various population groups may be affected differently in large Chinese cities. In Shanghai, where state owned enterprises (SOE) who have a strong hold on work unit type of land ownership coexist with private real estate developers who are maximizing profit by building market price housing, the jobs-housing balance can only be achieved through a competing advocacy of policy from multiple parties involved to align public interests and their own benefits. For example, in recent years, some local SOEs (who own land-use rights) collaborate with private developers (who bring money and development expertise) by forming public-private partnerships (PPP) to take advantage of mezzanine loans in the form of nominal bank debts. The PPP can expedite urban regeneration by providing more housing opportunities while reducing government debts.

Models 1, 2, and 3 all show access to future metro stations as a significant variable for property values. This factor considers future proposed metro stations and those under construction. The high positive coefficients in 2012 and 2017 mean at both points in time, the housing property prices are reflecting the premium of proximity to future metro stations. The negative coefficient for the 5-year price change, on the other hand, means that the premium price is reflected in the market at least 5 years before the metro station start operation and that price premium diminishes from that point on. The underlying reason may be that the initial market price was set too high so that it takes away future price growth potential. When the market functions well, the initial prices are confirmed by transactions, so they show what the market will bear. When the market fails to do so, it may be counted as a market failure.

Comparing access to existing metro stations with access to future proposed metro stations, access to existing metro stations is more influential in the short-term price variation. This can be explained by the fact that short-term decisions are a response to existing welfare while long-term decisions (more than one year) place more value on benefits that can be captured in the future.

Adequate public services such as post offices, public libraries, and banks provide convenient living experiences for residences (Jung, Huynh, \& Rowe, 2013). Convenient accessibility to these facilities is also reflected in housing prices (Huang \& Tao, 2015). In China, public service facilities are often associated with public space that can be utilized for social activities, for example, group exercise and plaza dance meetup. They are construed as valuable assets to the residents. However, the added value can diminish as public spaces become privatized or the re-intensification of urban space happens. 
Table 7: Regression models on price and price change over time

\begin{tabular}{|c|c|c|c|c|c|c|c|}
\hline & & & & Numb & er or & bservations & 31 \\
\hline & & Coef. & Std. Err. & $\mathrm{t}$ & $P>|t|$ & {$[95 \%$ Con } & Interval] \\
\hline P1 & Price 2012 & & & & & R-sqaured & 0.8215 \\
\hline Factor 1 & Jobs-Housing Relationship & $10,259.6$ & $1,174.6$ & 8.73 & 0.000 & $7,835.4$ & $12,683.9$ \\
\hline Factor 2 & Access to Existing Metro Stations & -824.1 & $1,302.4$ & -0.63 & 0.533 & $-3,512.2$ & $1,864,0$ \\
\hline Factor 3 & Access to Planned Metro Stations & $6,497.7$ & $1,426.6$ & 4.55 & 0.000 & 3.4 & $9,442.0$ \\
\hline Factor 4 & Typology & $4,639.8$ & $1,582.2$ & 2.93 & 0.007 & $1,374.3$ & $7,905.4$ \\
\hline Factor 5 & Public Amenity & $2,883.7$ & $1,744.2$ & 1.65 & 0.111 & -716.0 & $6,483.5$ \\
\hline Factor 6 & Environment Proximity & $2,502.6$ & $1,909.8$ & 1.31 & 0.202 & $-1,439.1$ & $6,444.3$ \\
\hline Cons & & $39,017.7$ & $2,496.8$ & 15.63 & 0.000 & $33,864.6$ & $44,170.9$ \\
\hline P2 & Pric & & & & & R-sqaured & 0.7853 \\
\hline Factor 1 & Jobs-Housi & 10. & $1,340.0$ & 7.63 & 0.000 & $7,459.8$ & $12,990.9$ \\
\hline Factor 2 & Access to Existing Metro Stations & $-3,552.3$ & $1,485.8$ & -2.39 & 0.025 & $-6,6$ & -485.8 \\
\hline Factor 3 & Access to $\mathrm{F}$ & $6,775.6$ & $1,627.4$ & 4.16 & 0.000 & 3,4 & $10,134.4$ \\
\hline Factor 4 & Typology & 4,2 & 1,8 & 2.35 & 0.028 & & $7,960.1$ \\
\hline Factor 5 & Public Ame & 1,8 & 9.7 & 0.94 & 0.355 & $-2,2$ & $5,984.4$ \\
\hline Factor 6 & Envir & 635.3 & 2,1 & 0.29 & 0.773 & -3 & $5,131.9$ \\
\hline Cons & & $65,602.8$ & $2,848.3$ & 23.03 & 0.000 & $59,724.2$ & $71,481.5$ \\
\hline P3 & Pric & & & & & & 0.2985 \\
\hline or 1 & Jobs- & 0 & 87 & 1 & & & 0.0466 \\
\hline Factor 2 & Access to Existing Mc & -0.0239 & 0.0540 & -0.44 & 0.663 & -0 . & 0.0876 \\
\hline Factor 3 & Access to $\mathbf{P}$ & -0.1419 & 0.0592 & -2.40 & 0.025 & -0.2640 & -0.0198 \\
\hline Factor 4 & Typology & -0.0745 & 0.0656 & -1.13 & 0.268 & -0.2 & 0.0610 \\
\hline Factor 5 & Publ & 81 & 0.0723 & -0.39 & 0.701 & & 212 \\
\hline Factor 6 & Environment Proximity & & & -1.27 & 0.218 & -0.2637 & 0.0633 \\
\hline Cons & & & & 9.01 & 0.000 & 0.7189 & 1.1463 \\
\hline P4 & & & & & & & 0.2283 \\
\hline Factor 1 & Jobs- & 0.0179 & 56 & 1.15 & 0.261 & -0 . & 0.0501 \\
\hline Factor 2 & Access to Existing Metro Stations & -0.0376 & 0.0173 & -2.18 & 0.040 & -0.0732 & -0.0019 \\
\hline Factor 3 & Access to Planned Metro Stations & -0.0008 & 0.0189 & -0.04 & 0.966 & -0.0398 & 0.0382 \\
\hline Factor 4 & Typology & 0.0059 & 0.0210 & 0.28 & 0.782 & -0.0374 & 0.0492 \\
\hline Factor 5 & Public Amenity & 0.0019 & 0.0231 & 0.08 & 0.934 & -0.0458 & 0.0496 \\
\hline Factor 6 & Environment Proximity & 0.0247 & 0.0253 & 0.98 & 0.338 & -0.0275 & 0.0770 \\
\hline Cons & & & & & 0.001 & 0.0507 & 0.1874 \\
\hline P5 & Pric & & & & & R-sc & 0.1649 \\
\hline Factor 1 & Jobs-Housing Relationship & & & & & & .0157 \\
\hline Factor 2 & Access to Existing Metro Stations & -0.0038 & 0.0050 & -0.77 & 0.451 & -0.0141 & 0.0065 \\
\hline Factor 3 & Access to Planned Metro Stations & -0.0009 & 0.0055 & -0.16 & 0.876 & -0.0121 & 0.0104 \\
\hline Factor 4 & Typology & 0.0043 & 0.0060 & 0.72 & 0.480 & -0.0081 & 0.0168 \\
\hline Factor 5 & Public Amenity & 0.0044 & 0.0067 & 0.65 & 0.519 & -0.0094 & 0.0181 \\
\hline Factor 6 & Environment Proximity & 0.0079 & 0.0073 & 1.08 & 0.291 & -0.0072 & 0.0229 \\
\hline Cons & & -0.0177 & 0.0095 & -1.86 & 0.075 & -0.0374 & 0.0020 \\
\hline
\end{tabular}




\section{$6 \quad$ Urban form and urban spatial structure}

Monocentric cities (Alonso, 1964) and polycentric cities (Garreau, 1991) have city centers or subcenters where the metro system can effectively connect people to concentrations of employment. Pudong, with a high percentage of within-district commuting trips, resembles a monocentric model. On the other hand, with nine employment centers, Shanghai performs more as a polycentric city. To describe the spatial structure of Shanghai more precisely, it is important to consider the large amount of work unit neighborhoods inherited from the pre-reform era and the dispersion of jobs outside of the employment centers. Angel and Blei (2016) proposed a mosaic of live-work and constrained dispersal model for contemporary cities. Pudong fits the description when considering its urban form and neighborhood development.

Density, one of the most frequently used measures for urban development, is a significant determinant for residential prices in 2012 and 2017. In the US, lower density subdivisions have higher prices; this study finds the reverse in Shanghai. Density in this study represents the maximum capacity of residence accommodated or the as-built condition (not the population density according to zoning). In a rapid urbanizing city, density should be constantly readjusted by policy makers and planning professionals to reflect surrounding environment change, job opportunity distribution, and accessibility improvement. The implementation of density adjustment, to a large extent, is a collective appropriation of the state apparatus and private investors' profit-making. Both neighborhood typology and size come into play as part of the urban land use right reform in China. Neighborhood typology exhibits stronger impact on price in 2012 than in 2017. It echoes the results from previous studies that in the long term mixed-use and diversity of land development are not as significant for Chinese cities as they are for American cities (Srinivasan, 2010). Neighborhood size, including both the land area and the number of residential units, exhibits significant effect on short-term (one year) price variation. To maintain a sustainable spatial structure, density, typology, and size should be further investigated in regard to urban development as well as urban retrofitting policies. More specifically, Pudong should adopt planning strategies that increase job accessibility by introducing higher diversity to accommodate all social classes. Also, Pudong should take into consideration spatial allocation of density to increase the overall compactness and emphasize TOD to balance future planned metro transit to serve not only high-income neighborhoods but also where low- to mid-incomes are clustered.

To summarize, there are three general planning strategies can be applied to promote sustainable urban spatial structure. First, enhance jobs-housing balance. This strategy should include promoting collaborations between public and private entities, introducing financial strategies such as nominal bank debts, and encouraging the mosaic live-work or cellular type model to constrain dispersal. Second, balance access to metro stations. This strategy not only considers the development stage variations among districts but also the density distribution around future planned metro stations. In particular, under the current "planning in advance" policy, the zoning ordinance and spatial plans of density distribution should reflect the public transit plan, both short term and long term. Third, use public space to reorganize the spatial planning of neighborhoods. The gravitational effect of social amenities can be applied to cultivate social capital, civic aspiration, and public participation. To be more specific, neighborhood design of different typologies should all provide convenient access to facilities.

\section{Conclusion}

In a market-oriented economy, urban form and accessibility interact with property value. To achieve a sustainable and more efficient urban spatial structure, residential housing price variation can be analyzed to understand variables of accessibility and urban form. This study shows that access to job, access to 
existing and future metro stations, access to public service, neighborhood density and size, and neighborhood typology are all influential factors. Especially jobs-housing balance and metro accessibility are the two key components to maintain a functionally efficient, economically viable, and socially equitable urban spatial environment at the neighborhood scale.

The limitations of this study include not differentiating the status of metro stations (transfer versus non-transfer stations), quality of school district, and property management structure. In sum, urban development policies, zoning ordinances, and rapid transit investment should align with the spatial distribution of jobs, public amenities, neighborhood density, size, and typology, in order to achieve a sustainable urban spatial structure.

\section{Acknowledgments}

This research received supports from the Harvard-China Project on Energy, Economy and Environment of the Harvard John A. Paulson School of Engineering and Applied Sciences and the Harold A. Pollman Fellowship of Graduate School of Design, Harvard University. We are grateful for the support to the Harvard-China Project of the Harvard Global Institute, under an award on the theme of "China 2030/2050: Energy and Environmental Challenges for the Future." 


\section{References}

Alonso, W. (1964). Location and land use. Cambridge, MA: Harvard University Press.

Angel, S., Parent, J., Civco, D. L., \& Blei, A. M. (2012). Atlas of urban expansion. Choice Reviews Online, 50(3), 397.

Angel, S., \& Blei, A. M. (2016). The spatial structure of American cities: The great majority of workplaces are no longer in CBDs, employment sub-centers, or live-work communities. Cities, 51, 21-35.

Boarnet, M. G. (2011). A broader context for land use and travel behavior, and a research agenda. Journal of the American Planning Association, 77(3), 197-213.

Cao, X. (Jason), Mokhtarian, P. L., \& Handy, S. L. (2009). The relationship between the built environment and nonwork travel: A case study of Northern California. Transportation Research Part A: Policy and Practice, 43(5), 548-559.

Cervero, R. (1996). Jobs-housing balance revisited: Trends and impacts in the San Francisco Bay Area. Journal of the American Planning Association, 62(4), 492-511.

Corder, G. W., \& Foreman, D. I. (2014). Nonparametric statistics: A step-by-step approach. John Hoboken, NJ: Wiley \& Sons

Diao, M., \& Ferreira, J. (2010). Residential property values and the built environment: Empirical Study in the Boston, Massachusetts, metropolitan area. Transportation Research Record: Journal of the Transportation Research Board, 2174, 138-147.

Diao, M. (2015). Selectivity, spatial autocorrelation, and the valuation of transit accessibility. Urban Studies, 52(1), 159-177.

Diao, M., Leonard, D., \& Sing, T. F. (2017). Spatial-difference-in-differences models for impact of new mass rapid transit line on private housing values. Regional Science and Urban Economics, 67, 64-77.

Dong, H. (2017). Rail-transit-induced gentrification and the affordability paradox of TOD. Journal of Transport Geography, 63, 1-10.

Ewing, R. and Cervero, R. (2010). Travel and the built environment. Journal of the American Planning Association, 76 (3) 265-29.

Feng, J., Dijst, M., Prillwitz, J., \& Wissink, B. (2013, November). Travel time and distance in international perspective: A comparison between Nanjing (China) and the Randstad (The Netherlands). Urban Studies, 50, 2993-3010.

Garreau, J. (1992). Edge city: Life on the new frontier. New York: Anchor Books Inc.

Guan, C., \& Rowe, P. G. (2016). The concept of urban intensity and China's townization policy: Cases from Zhejiang Province. Cities, 55, 22-41.

Guan, C., \& Rowe, P. G. (2018). In pursuit of a well-balanced network of cities and towns: A case study of the Changjiang Delta Region in China. Environment and Planning B: Urban Analytics and City Science. doi.org/10.1177/2399808317696073

Guan, C. (2018) Spatial distribution of high-rise buildings and its relationship to public transit development in Shanghai. Transport Policy. In press.

Giuliano, G., \& Small, K. A. (1993). Is the journey to work explained by urban structure? Urban Studies. 30 (9), 1485-1500.

Handy, S., Cao, X., \& Mokhtarian, P. (2005). Correlation or causality between the built environment and travel behavior? Evidence from Northern California. Transportation Research Part D: Transport and Environment, 10(6), 427-444.

Hess, D. B., \& Almeida, T. M. (2007). Impact of proximity to light rail rapid transit on station-area property values in Buffalo, New York. Urban Studies, 44(5-6), 1041-1068.

Hu, L., Fan, Y., \& Sun, T. (2017). Spatial or socioeconomic inequality? Job accessibility changes for low- and high-education population in Beijing, China. Cities, 66, 23-33. 
Hu, L., Sun, T., \& Wang, L. (2018). Evolving urban spatial structure and commuting patterns: A case study of Beijing, China. Transportation Research Part D: Transport and Environment, 59, 11-22.

Huang, Y., \& Tao, R. (2015). Housing migrants in Chinese cities: Current status and policy design. Environment and Planning C: Government and Policy, 33(3), 640-660.

Jung, S., Huynh, D., \& Rowe, P. G. (2013). The pattern of foreign property investment in Vietnam: The apartment market in Ho Chi Minh City. Habitat International, 39, 105-113.

Li, J., Walker, J. L., Srinivasan, S., \& Anderson, W. P. (2010). Modeling private car ownership in China: Investigation of urban form impact across megacities. Transportation Research Record: Journal of the Transportation Research Board, 2193, 76-84.

Ma, J., Liu, Z., \& Chai, Y. (2015). The impact of urban form on CO2 emission from work and nonwork trips: The case of Beijing, China. Habitat International, 47, 1-10.

Montgomery, D. (2001). Design and Analysis of Experiments (5th ed.). New York: Wiley.

Pan, Q. (2013). The impacts of an urban light rail system on residential property values: A case study of the Houston METRORail transit line. Transportation Planning and Technology, 36(2), 145-169.

Pan, H., Shen, Q., \& Zhang, M. (2009). Influence of urban form on travel behavior in four neighborhoods of Shanghai. Urban Studies, 46(2), 275-294.

Peng, Z .R. (1997). The jobs-housing balance and urban commuting. Urban Studies. 34 (8), 12151235.

Peiser, R. B. (1989). Density and urban sprawl. Land Economics, 65, 193-204.

Petrisor, A., Ianos, I., Iurea, D., \& Vaidianu, M. (2012). Applications of principal component analysis integrated with GIS. Procedia Environmental Sciences, 14, 247-256.

Smith, W. (1986). Interactions between transportation and high-rise, high-density living. Ekistics, 53(320/321), 336-344.

Srinivasan, S. (2010). Linking travel behavior and location in Chengdu, China: Geographically weighted approach. Transportation Research Record: Journal of the Transportation Research Board, 2193, 85-95.

Wang, D., \& Chai, Y. (2009). The jobs-housing relationship and commuting in Beijing, China: The legacy of Danwei. Journal of Transport Geography, 17(1), 30-38.

Wang, D., Chai, Y., \& Li, F. (2011). Built environment diversities and activity-travel behavior variations in Beijing, China. Journal of Transport Geography, 19(6), 1173-1186.

Wang, D., \& Zhou, M. (2017). The built environment and travel behavior in urban China: A literature review. Transportation Research Part D: Transport and Environment, 52, 574-585.

Wang, E., Song, J., \& Xu, T. (2011). From spatial bond to spatial mismatch: An assessment of changing jobs-housing relationship in Beijing. Habitat International, 35(2), 398-409.

Weitz, J. (2003). Jobs-housing balance. American Planning Association: Planning Advisory Service Report, Chicago.

World Bank (2010). Cities and climate change: An urgent agenda. Urban development series. Washington, DC: The World Bank, International Bank for Reconstruction and Development.

Yang, J. (2010). Spatial and social characteristics of urban transportation in Beijing. Transportation Research Record: Journal of the Transportation Research Board, 2193, 59- 67.

Yang, J., Chen, J., Le, X., \& Zhang, Q. (2016). Density-oriented versus development-oriented transit investment: Decoding metro station location selection in Shenzhen. Transport Policy, 51, 93-102.

Yang, J., Shen, Q., Shen, J., \& He, C. (2012). Transport impacts of clustered development in Beijing: Compact development versus overconcentration. Urban Studies, 49(6), 1315-1331.

Yang, Z., \& Chen, J. (2014). Housing affordability and housing policy in urban China. New York: Springer.

Zhao, P. (2014). The impact of the built environment on bicycle commuting: Evidence from Beijing. Urban Studies, 51(5), 1019-1037. 
Zhao, P., Lu, B., \& de Roo, G. (2011). Impact of the jobs-housing balance on urban commuting in Beijing in the transformation era. Journal of Transport Geography, 19(1), 59-69.

Zhong, H., \& Li, W. (2016). Rail transit investment and property values: An old tale retold. Transport Policy, 51, 33-48.

Zhu, Y., \& Diao, M. (2016). The impacts of urban mass rapid transit lines on the density and mobility of high-income households: A case study of Singapore. Transport Policy, 51, 70-80. 